\title{
Masculinities and experimental practices in physics: The view from three case studies
}

\author{
Allison J. Gonsalves, ${ }^{1, *}$ Anna Danielsson, ${ }^{2}$ and Helena Pettersson ${ }^{3}$ \\ ${ }^{1}$ Department of Integrated Studies in Education, McGill University, \\ 3700 rue McTavish, Montreal, Quebec H3Y 1A2 Canada \\ ${ }^{2}$ Department of Education, Uppsala University, Box 213675002 Uppsala, Sweden \\ ${ }^{3}$ Department of Culture \& Media Studies/Ethnology, Umeå University, SE 90187 Umeå, Sweden
}

(Received 30 January 2015; published 1 August 2016)

\begin{abstract}
[This paper is part of the Focused Collection on Gender in Physics.] This article analyzes masculinity and experimental practices within three different physics communities. This work is premised on the understanding that the discipline of physics is not only dominated by men, but also is laden with masculine connotations on a symbolical level, and that this limited and limiting construction of physics has made it difficult for many women to find a place in the discipline. Consequently, we argue that in order to further the understanding of gender dynamics within physics communities and enrich the current understandings about the lack of women in physics, perspectives from masculinity studies are crucial. The article draws on three different ethnographic case studies dealing with undergraduate students, graduate students, and research scientists.
\end{abstract}

DOI: 10.1103/PhysRevPhysEducRes.12.020120

\section{INTRODUCTION}

The cultural practices of experimental physics communities have been well studied from the perspective of anthropologists, sociologists, and educational researchers alike, Refs. [1-3]. In particular, the gendering of physics practices within these communities have been described by researchers seeking to understand both the production of gender through these practices and the subsequent domination of men in the field in both rank and number [4]. The association of physics with men and also masculinity has been widely documented by feminist science scholars and educational researchers alike [3,5-8]. Keller has suggested that our current dualistic understanding of gender and science renders a situation where "any scientist who is not a man walks a path bounded on one side by inauthenticity and on the other by subversion" [5] (p. 174). According to Keller, this critical problem of identity stems from the unproblematic association of masculinity with science, and, therefore, the problematic association of femininity with science. Similarly, physics, as a designated hard science, is often positioned in popular discourse as incompatible with femininity [9]. The strong associations between femininity and women thus render feminine women as incompatible with physics in public understandings of who is able to participate in the discipline [10]. While the focus of this study is on physicists and physics students' navigation of gender, we will not be

\footnotetext{
*Corresponding author. allison.gonsalves@mcgill.ca

Published by the American Physical Society under the terms of the Creative Commons Attribution 3.0 License. Further distribution of this work must maintain attribution to the author $(s)$ and the published article's title, journal citation, and DOI.
}

attending to whether participants perceive the culture of physics as a masculine one. The masculine connotations associated with physics have been well established in previous work (as indicated above). Rather, we focus on how different masculinities are produced and valued in relation to physics practices in various experimental subpractices.

\section{A. Masculinity and the problem of gender in physics research}

Relatedly, the association of masculinity with physics has created gendered roles for men and women in physics communities. Traweek [1], for example, conducted a multisite ethnography of high-energy physicists to explore how physicists (undergraduates, graduate students, postdoctorates, and researchers) learn, produce, and reproduce the culture of physics across time, and how these cultural processes reproduce the gendered divisions of labor in broader society. Likewise, Hasse [3] similarly conducted an ethnographic study of physics classrooms to explore issues of inclusion and exclusion in physics communities. Hasse argued that physics education embodies an understanding of physics as a masculine activity, and that this manifests in a jovial brotherhood, characterized by playfulness, creativity, and initiative - characteristics that were more often attributed to men than to women.

Danielsson [11] has argued that gender-focused research in physics education has tended to focus on gender as a stable variable that results in comparing the experiences of men and women, rather than exploring the variability of experiences across genders. The result of this binary focus on gender is a tendency to see gender as a woman problem that can be resolved with female-friendly solutions. This kind of work constructs two different kinds of physics 
learners: male students who enjoy the abstract and practical work of physics and female students who look to relate physics to in their own lives and who have lower selfconfidence, specifically towards practical work [12].

According to Pettersson [4], it is important to not only focus our unit of analysis on women's accomplishments and struggles within male dominated disciplines like experimental physics. Men and cultures dominated by men within academic disciplines and research communities should also be analyzed as political categories and political subjects. In order to understand why physics in particular is still dominated by men, the cultures and actions that are associated with masculinity are analyzed. Through the daily practices and the hands-on situations, experimental physics practices as labor are associated with men and masculinity, and performed in a context that abundantly speaks of a masculinized environment.

\section{B. Learning as identity construction}

This article shifts the traditional perspective on physics learning from concept acquisition to identity construction. Traditionally, in science and physics education research students' constitutions of conceptual and procedural knowledge is a central area, and the fields remain dominated by individualized perspectives of learning. Recently, science education has expanded to include issues of epistemology and affective factors (such as students' science attitudes and perceptions of science and scientists) [13], and recent work published in PRST-PER expands physics education research beyond the cognitive realm to highlight the salience of identity construction as salient to membership and persistence in the field [14].

We understand that learning in physics entails the construction of conceptual knowledge, but also the construction of identities as insiders to a disciplinary field. Deciding to be a "certain kind of person" [15] and then carrying out activities to garner recognition as a member of that community is a critical part of learning to be a physicist [16]. Models of identity construction taken up by PER point to the salience of recognition and performance in physics learning outcomes, Ref. [17], and conceptualize physics identities as "how someone perceives themselves with respect to the field of physics" [18] (p. 329). Our emphasis on masculinities and physics practice in this article puts the notion of learning as identity construction in focus, against a backdrop of discourses that construct gendered notions of what it means to practice physics. In this way, we can explore how discourses of gender shape physics practitioners' identity trajectories in physics. Our case studies presented here provide stories of physics students who constitute and negotiate discourses of masculinity and femininity in heterogeneous and subversive ways.

We have chosen to present these stories as case studies to provide an in-depth examination of the navigation of discourses of masculinity across different contexts. The presentation of these stories as case studies permits us to zoom-in on the experiences of physics practitioners over a period of time, and also permits the construction of narratives from a variety of data sources and collection methods [19]. While we present stories of men and women doing physics across undergraduate, graduate, and research levels, we take as our common lens the practice of doing physics in various laboratory settings. The focus on the laboratory is salient as undergraduate and graduate students, as well as researchers, spend considerable time in the laboratory and are required to develop competence in a range of experimental skills [1]. Not only is laboratory work related to conceptual knowledge construction in physics, it also provides a means by which students are apprenticed into the community of experimental physicists, which is also a process of enculturation into the community [20].

\section{THEORETICAL FRAMING}

All three of the case studies presented here emerge from sociocultural understandings of learning physics as identity construction. In developing a theoretical framework that threads throughout all three of these studies, we drew on understandings of doing physics practice as the doing of identity, thus suggesting that engaging in physics practices entails a performance that is tied to identity construction. This perspective emerges from sociocultural theories of activity and identity that suggest that who one is cannot be understood independently of the social and material situation that persons are embedded in, or the activity they are engaged in $[21,22]$. In these three cases, we see identity as salient to understanding how participants navigate discourses of gender, and particularly how they constitute identities in relation to various forms of masculinities that are produced and reproduced in physics laboratory settings.

\section{A. Identity}

As we are focused on laboratory learning, we explore the constitution of identities within laboratory spaces, and consider the ways that lab practices (conceptual learning, learning and application of skills) may also constitute the negotiation of disciplinary norms, including but not limited to gendered norms, in those spaces. Identity, in the everyday sense of the word, may signal something rather static. However, deliberately positioning ourselves in this paper within a sociocultural framing of identity, we understand identity not as a stable category but as a negotiated experience that is constituted in relation to practices. We may think of identity performances as bids for recognition [23], wherein a successful bid to be recognized as a certain kind of person by meaningful audience members would align with the recognizable identities in that field, and in turn influence whether or not the actor begins to think of 
themselves as a certain kind of person. Paechter [24] explains,

Identity can in this way been seen as being related to a competent and convincing performance of a particular role; it is defined not just internally by the individual but externally by the group's inclusive or exclusive attitude to that individual. (p. 74)

Identity, from this perspective, is constituted in an intersection of discourses concerning, for example, gender, sexuality, social class, (dis)ability, and ethnicity. Such discourses limit the possible identity positions available to us and make us submit to certain norms, but it is also these discourses that make identity positions possible. In this study, we make use of the concept of identity trajectories [25] to signal that learning physics through laboratory practices is as much a process of identification with physics practices and careers as it is about concept acquisition and skill development. We discuss this process of becoming as a trajectory into physics that entails the construction of an identity as a "physics kind of person." Wenger discusses trajectories of identification as inbound, outbound, or peripheral, indicating the route an individual takes towards membership in a community of practice. We find this conceptualization of identity salient to our own exploration of how participants navigate stories of what it takes to be recognized as a good physicist, and construct identities as insiders to physics.

\section{B. Gender and performativity}

In this article we focus specifically on gender, and, in particular, the construction of masculinities. In doing so, becoming physicists is seen as a complex negotiation of doing physics and simultaneously doing gender [26]. The lens we take on gender as socially constructed helps us to think about doing both physics and gender as a process of identification that involves competently and convincingly performing a role that is recognizable to both the performer and their audience [24]. Drawing from feminist poststructural theory, we see gender as performative and fluid and we also take up Butler's [27] challenge to trouble the binary categories around which gender can be constituted. A performative perspective on gender implies that we understand gender to be a trait or characteristic that we perform in response to situational contexts, not a static or unchangeable essence that we possess. Thus, gender can be fluid in that it may be enacted in different ways in response to different contexts. We may change our gender performances over our lifetimes, across situations, or in interactions with different people. For Butler, gender is something that is enacted or performed-it is done, just as physics is done as a practice. Gender is performed through behavior, dress, speech, career choices, interests, and many other enactments. Similarly, physics can be performed through dress, speech, behavior, skills, career choices, etc. Butler suggests that identification (with a gender, or by extension with a field of study or group of people) involves a negotiation of possible identities that are simultaneously imposed and taken up. But, Paechter [28] suggests that the ways in which it is possible to successfully do gender are limited by the acceptable forms of masculinities and femininities in a community. Paechter makes the important distinction between masculinity and femininity as collective ideals about what it means to be a male or a female in a particular local context, and masculinities and femininities as the way that people do boy or girl, or, man or woman. Thus, gender is understood not as a static trait that one possesses, but rather as something that is constructed between individuals in various social settings.

It is important that we take this perspective on gender, in particular, that it is a fluid and dynamic experience rather than a binary and stable one, because this perspective speaks to the huge diversity of gender performances present in any context. Physics laboratories are no exception to this. Faulkner [29] suggests that the dichotomous generalities that are made about "men" and "women" are never shown to be sustained. Rather, gender is relational, local, and how they are performed in different contexts speaks to the potential of that context to limit or enable identities that are also shaped by gender. This perspective of gender helps us look more carefully at the complexities of gendered experiences in physics environments, rather than simply asking questions about what women need to succeed in physics. Those types of questions invariably boil down to stereotypical assumptions about how women work or think or how men work or think, and how can women can change to be more successful in a male dominated culture. Moving away from a binary and static view of gender can open up the kinds of questions researchers can ask about the experiences of gender and how these vary across contexts. This is particularly important for the laboratory environment, which is a dynamic environment where participants perform various identities related to physicists that interact with gender in varying ways. A sociocultural theory of gender grounded in performativity thus informs the ways that we attempt to unpack the nuances of participants' doing of gender at the same time as we understand their doing of physics.

\section{Masculinities}

In this article, we discuss masculinities, rather than the singular masculinity, to imply that we understand conceptions of masculinity as a construct that is complex and varied across social and cultural contexts. Connell and Messerschmidt [30] have developed this understanding of multiple masculinities, where masculinity should be understood in relation to a larger system of cultural and social practices. It is crucial to emphasize that all masculinities are not created equal; there are hierarchies between men as 
individuals and different groups of men, and different masculinities are expressed and performed [31,32]. The construction of masculinity, however, is often not culturally viewed as a performance (and therefore not multiple or hierarchical), and is instead viewed as a characteristic that men naturally possess by virtue of their sex. Halberstam [33] argues that men derive great power from assuming and confirming that masculinity is nonperformative. If masculinity is a characteristic inherent to being a man, then it cannot be constructed or performed, it must be natural and exclusive to men. The perceived nonperformativity of masculinities is also helpful for exploring how masculinities are understood through the practice of physics. A static and nonperformative idea of masculinity may be associated with many of the valued attributes also associated being a physicist. Wacjman [34] has suggested that technical competence is associated with a performance of masculinity that is "based on physical toughness and mechanical skills" (p. 143). She has also pointed to machine-related skills and physical strength as being measures of masculine status. Similarly, Wacjman has also suggested that another type of competence that is associated with traditional understandings of masculinity draws on cultural understandings of analytical competence. She suggests that this attribute is the one of "professionalized, calculative rationality" (p. 144). We therefore draw on Wacjman's [35] ideas of technical and analytical masculinities to frame our understandings of the ways in which masculinity is understood and performed through the practices of physicists. Our understanding of masculinity as a performance-rather than a static trait assigned to men only-allows us to thus examine the ways that both men and women take up these skills or transform them in order to gain recognition as competent physicists through laboratory practice. However, as Halberstam's work reminds us, masculinity may not always be viewed as multiple and performative, so we keep this formulation of masculinity in mind as we analyze physicists' conceptions of gender and physics practices.

\section{Making connections}

Each of the case studies presented below make use of this theoretical framework to support an interpretive analysis of participants' words and actions in their physics practice. Case study 1 presents interview data that when viewed through a research lens that foregrounds an analysis of gender, demonstrates how the practices that physics students value tend to be those associated with stereotypical forms of masculinity. Thus, doing physics in acceptable ways also entails doing masculinity. Danielsson makes connections between the doing of these practices with students' identity trajectories into physics careers. This case study also makes use of this framework to discuss how masculinity can be transformed in physics practices, in ways that point to the nonbinary and performative nature of gender.
Case study 2 presents ethnographic data that similarly supports the perspective that physics students (this time at the doctoral level) value skills that are typically associated with stereotypical forms of masculinity. This case portrays two students who navigate identity trajectories that involve the performance and sometimes transformation of masculinities associated with competence in their respective fields. These masculinities are revealed through examples of participants' stories about how skilled physicists are recognized, either through their work with instruments or through narratives about what one must look and act like in order to successfully pull off a physicist performance.

Case study 3 makes use of this framework by focusing on how practicing physicists view their identity trajectories from school age onward. Petersson initially presents participants' ideas about gender-that the masculinities associated with physics practices are naturally associated with men, and therefore binary and static-and then presents us with examples of how this understanding of gender then pervades (and corrupts) laboratory life. This analysis confirms that conceptions of masculinity among physicists corresponds with Halberstam's [33] argument that men derive power from confirming that masculinity is nonperformative, and by extension that these skills are natural to men only, confirming the binary nature of gender. This case demonstrates the pervasive and normative ideology of masculinity in physics, and presents an example of the difficulties women physicists face as they navigate this ideology.

\section{METHODOLOGY}

This article draws on three different case studies, all exploring gender making processes in laboratories and workspaces where physics is practiced. The first case study was carried out in Sweden (Danielsson), the second in Canada (Gonsalves), and the third in the United States (Pettersson).

The first case study makes use of semistructured interviews [36] with thirteen undergraduate and nine graduate students. At the time of the interview the graduate students were either working on their Master's projects or had recently begun a Ph.D. program. The interviews lasted between 30 and 70 minutes and were audio recorded and transcribed verbatim. The selection of interviewees was strategic, aiming to include a diversity of students (men and women, different ages, and educational backgrounds). While the actual data collection was limited to interviews, Danielsson's own background in physics can be said to serve a purpose somewhat similar to that of participant observations, in that it allowed her to build a trusting relationship with the interviewees in relation to shared experiences (particularly pertinent in the interviews with women) and contributed to making more nuanced explorations of the interviewees' experiences of their physics educations possible and meaningful. The methodology for 
the first case study is described in detail in Ref. [37]. The data that are predominantly used in this article consist of interviews with four students (two men and two women).

The second case study made use of multiple sources of data, primarily ethnographic field notes, journaling, photoelicitation interviews and semistructured interviews. Over the course of one year, field observations and interviews were conducted with eleven men and women across a variety of disciplinary subfields in one physics department. These men and women were at various stages of degree completion for doctoral degrees, and came from astrophysics, theoretical high energy particle, and solid state physics fields. The men and women participants were selected based on their disciplinary field and stage of degree completion. All of them permitted the Gonsalves to spend substantial amounts of time in their labs and offices, meetings, social events, and academic gatherings. They all engaged in two semistructured interviews with the author, one midway during the field work, and one at the end. Interviews were transcribed verbatim as were field notes. A complete description of the methodology can be found in Ref. [38].

The third case study was based on ethnographic field work with long-term following observations and in-depth interviews. The deep interviews were conducted with 15 persons in the lab with the length ranging from 2 to 5 hours. The interviews were recorded, transcribed, and then carefully interpreted in themes. The key informants participating in the deep interviews were professors, senior and junior staff scientists, and Ph.D. students. Two of them were women, 13 were men. The interviews took place in a meeting room at the lab. It was a more neutral space than an office, without phone or computer to distract. Most interviews were conducted in one long sweep including small breaks. However, for some people, it was hard to find several hours in a row, which is why the interviews were conducted in two or three parts. The list of questions included details about their work and practices, but also about gender. While doing field work, Pettersson was present during ordinary workdays observing experiments, and workshop labor. Pettersson sat in during seminars, office work, and meetings. The field note data include not only observations but also conversations and shorter interviews with physicists visiting the lab as visiting researchers. Pettersson also conducted field work during a national Plasma Physicists' Conference, with observations throughout the conference events, and conducted short interviews with eight physicists $[4,39]$.

\section{A. Analysis}

Analysis of the data was performed on a case-by-case basis, and involved thematic analysis of the interview data, and the collection of themes to construct narratives of experience. We did not make attempts to look for themes across the different cases, but rather present these studies as stand-alone examples of the various ways that individuals negotiate masculinities in physics. Our discussion section highlights the various gender dynamics within physics communities and pays particular attention to the ways that attending to masculinities in physics can help us to better understand the nuanced processes of doing physics and doing gender.

\section{B. Research sites}

The first case study was carried out at an old, traditional university in Sweden. The university is a well-established research university. Its physics research is seen as a high status activity both within and outside the university. Traditionally, the university's physics research has been centered on experimental physics, and today's physics research is carried out within a wide range of both theoretical and experimental subdisciplines. There is one undergraduate degree program and two engineering programs strongly focused on physics; all undergraduate students interviewed for the study were enrolled in the undergraduate degree program. About one-quarter of the students in the undergraduate degree program are women, among the physics professors about $7 \%$ are women.

The second case study takes place in the physics department of a research-intensive university in Eastern Canada. The department provides programs in theoretical, observational, and experimental astrophysics, biological physics, condensed matter, theoretical and experimental high energy physics, theoretical and experimental nuclear physics, as well as nonlinear, applied, and medical physics. The Ph.D. program is a traditional research-based program, which students take an average of 4 to 5 years to complete.

The third case study is situated in the United States, with field work conducted in a large university laboratory in plasma physics. A university laboratory is smaller compared to the Big Science laboratories but may still maintain large experimental facilities like tokamaks and accelerators. Central for this case was a building with devices and rooms for plasma processing, laser experiments, and a huge hall with a workshop with machines and experimental devices. The device itself is almost 20 meters long and produces quiescent, highly ionized plasma, and the central experimental feature at the site. Most people at the field site conducted experimental basic plasma physics; a few conducted more experimental fusion oriented physics.

\section{CASE STUDIES}

\section{A. Case study 1: Sweden}

The first case study explores how male and female undergraduate and graduate physics students at a Swedish university negotiate the practices of the physics student and research laboratories and their own participation in these practices. The analysis is organized around two different themes constructed from the entire data set, but for clarity 
excerpts from four students will figure in this section. This case study illustrates, first, the construction of masculinity as it is associated with technical or physical skill; and, second, the affordances and constraints that the masculinization of physics poses on the identity performances of female-identified students in physics. These findings draw on Wacjman's theoretical constructions of analytical and technical skills that are unproblematically related to associated masculinities.

\section{The (non)importance of tinkering}

Laboratory work is often considered as a central part of university science education, in that it presents a unique opportunity to learn the essentials of scientifically based empirical activity [40]. However, the complexity of this learning context makes varying interpretations of the learning goals possible [20] and one of the most notable dividing lines among the interviewed students is whether they consider practical skills as essential to laboratory work or not. Several students are very adamant that practical skills are of little or no importance in the student laboratory, focusing entirely on the importance of mathematical and analytical skills.

However, there is also a subset of students who talk about their own practical skills as highly important within the laboratory setting. The undergraduate student Paul says that what he is skilled at in the student laboratory is "connecting stuff," to get the experiments going and doing measurements, referring to his experiences from carpentry and plumbing as important for how he works in the student laboratory. The Ph.D. student Cecilia describes her approach to laboratory work in a very similar fashion, saying that what she is good at is "daring to press all the buttons," whereas she, as an undergraduate student, seldom was particularly well prepared for the laboratory work. This approach to laboratory work further resembles the playful approach to physics [3] in her ethnographic study found exclusively among groups of male students. The Master's student Kalle stresses his background in industrial work as important for the way he does physics and by likening the research laboratory to a workshop, the workshop serves as a boundary object [41] for Kalle:

\section{I: What do you see as so appealing with the exper- imental then?}

Kalle: Erm...It's this that...you can come up with solutions yourself then, and then you get...to manufacture these ideas then, even though it's not me who gets to do it, but it's the people in the workshop... But it is precisely that that's so appealing, that it's so close to working in a workshop really...

Similarly, the Ph.D. student Anne characterizes her project as "extremely experimental" and views her experiences of working with construction of electrical equipment as highly valuable. But, while all these students clearly value their own practical skills, Paul and Kalle view the status of these abilities within the physicist community differently. Kalle repeatedly returns to the importance of practical abilities, in terms of both how he does physics and how he thinks that physics ought to be done, even though he thinks that his practical skills are not always fully valued within the physicist community. Furthermore, he also positions himself in opposition to an approach focused on looking for "too much" understanding (something that hinders quickly finishing a laboratory exercise). However, he does recognize that his approach to laboratory work and the skills he brings sets him aside from most physicists:

Kalle: ....at least now that I'm doing my Master's research project I can say that I work in a different way compared to how ordinary scientists work so to speak, especially since you get to do a lot of tinkering yourself.

Paul also values his practical skills highly, but has experienced that these are not always as highly valued by the physicist community, and says that he is working on developing his analytical skills. By doing so, Paul aspired to be on an inbound trajectory in the physicist community of practice [25], negotiating a kind of participation in physics where he complied with collective norms about the importance of analytical skills, yet questioning the perceived devaluing of practical skills.

Noticeable is also how both Kalle and Paul, despite being men, and as such often being assumed to have an unproblematic relationship to the discipline of physics [42], are involved in negotiations of how to fit into the discipline. One interpretation of this is that it is an effect of different masculinities being valued within different class contexts. Thus, negotiating a participation in physics drawing on the practical aspects of the discipline could not only be seen as related to these students' experiences of working-class jobs, but also a doing of gender. The similarities between Anne's, Cecilia's, Paul's, and Kalle's approaches to laboratory work and the associated identity negotiations are notable, and to some extent all four of them can be said to perform the technical masculinity described by Ref. [34]. By drawing on the practical aspects of the physicist practice, all four students were able to negotiate a participation in university physics in which they were holding onto technical skills they had learned to value in their working-class backgrounds. The connection between technical skills and the performance of masculinity has also been made by, for example, by Refs. [29,43,44]. To exemplify, in the study by Mellström, Swedish engineers described technical skills as an important part of what it means to be a competent man [43]. Mellström further argues that the ideal of being able to take care of a wide range of practical problems can be found in a wide range of 
social contexts, but is more prominent in rural areas and smaller towns and in working class contexts. In summary, Mellström concludes that, in Sweden, being practical has traditionally been valued highly and is also tightly interconnected with "being a man."

\section{Female masculinity in physics}

Anne and Cecilia repeatedly describe themselves as "laddish," distancing themselves from all-female contexts and stressing how they feel at home in male-dominated contexts, such as physics:

Ann: I like being among guys, I like that jargon and that attitude a lot of the time, I would be more nervous if it was only women. I've had a horse you know. Only women in a stable. Not so easy, I can tell you.

This is well in line with how Refs. [45,46] and others have noted that women within male-dominated science and technology disciplines often position themselves as "one of the boys," thereby distancing themselves from a traditional femininity that is perceived as incompatible with doing science or engineering. Such distancing is often seen as a way for these women to fit into their science or technology discipline, and sometimes also understood as a failure to challenge dominant gender norms [45] or even as an approach forced on to the women [47].

However, given the strong and positive identification of Anne and Cecilia with the technical masculinity described by Wacjman [34] and how this way of doing physics constitutes a continuity to their previous experiences for these self-identified working-class students, we would like to offer a different interpretation. First, it can be noted that women science and mathematics students are often constructed as diligent, neat, and rule following as well as hard working, rather than talented $[48,49]$. When Cecilia talks about her practice in the student laboratory as being characterized by inadequate preparation and unafraid tinkering with the equipment, we would argue that this in part needs to be understood as a reaction towards the norm for female science students, well in line with how she describes herself as laddish. Both by an explicit rejection of the rulefollowing approach to laboratory work commonly attributed to female students and by rejecting "traditional femininity" in more general terms, for example, by pointing out how she was a typical engineering student who "drank beer and sang indecent songs," Cecilia is in several ways performing a "female masculinity" [33]. Similarly, Anne has in the physics community also found an arena where her desired way of being is possible, she repeatedly stresses how she feels at home in the physics community and also says

Ann: I can never be like normal [women] [...] So I feel very comfortable among guys...
In conclusion, then, it can be argued that physics not only offers constraints for the performance of certain kinds of femininities, but also affordances for identity performances that are in contrast to these femininities.

\section{B. Case study 2: Canada}

The second case study takes place in a Canadian university and reveals how gender can be inscribed onto the equipment used by graduate students in physics laboratories in ways that delegate gendered roles, actions, and responsibilities to those who use it. Evidence from this study also points to the gendered construction of the stereotypical physicist, and the weight that this carries when one attempts to gain recognition as a member of the field. This study paid attention to the ways that male and female doctoral students performed physicist at the same time as they performed masculinities and femininities in ways that challenged and sometimes transformed the norm. Emerging from observational and interview data, we see examples of doctoral physics students constructing and performing physicist identities by making bids for recognition as competent by reworking or reproducing masculine ideals of competent physicist. Drawing on Carlone and Johnson's [16] constructions of science identities, this case makes use of the theoretical concepts competence and recognition. In this case, we focus on ways that participants position themselves as competent, for the purpose of recognition as a "good physicist." We also present an example of a student who improvises when she cannot position herself as competent in acceptable or recognizable ways.

Though there were 11 men and women participating in this study, this case focuses on two examples of female students negotiating the male-dominated discipline of physics in ways that refigure and reproduce masculinities and femininities in the field. These two examples were selected as they demonstrate two very different approaches to gaining recognition in the field, and they also grapple (implicitly and explicitly) with the masculinities inscribed in the field. The first is an example a doctoral student developing expertise on laboratory equipment that is designed with gender in mind. The second is an example of a doctoral student who rejects traditional forms of femininity and associates herself quite strongly with the dominant masculine ideal of the field. The first example demonstrates how technical competence, which is associated with the use of instruments in the physics lab, can also become associated with masculinity. In this way, laboratory equipment use can construct possible identity positions for physically skilled physicists that point to machine-related skills and physical strength as measures of masculine status. The second example demonstrates how a strong rejection of traditional femininity can also be an identity move to position oneself as a recognizable physicist. 


\section{Machines designed with gender in mind}

In this case, we see an example of a students' negotiation of a tool that is designed in ways that delegate gendered roles based on physical attributes. Lily, a 4th year Ph.D. student at Eastern University (a large research-intensive university in Eastern Canada), identified the limitations that requirements for physical skill pose for individuals who are not big or strong enough to manipulate the instrument used in her line of work. To illustrate this, Lily described a trip to a lab in Germany to work on a collaborative research project. She was bringing to the project a skillset that she had developed on the Scanning Tunneling Microscope (STM) she had worked with in Canada, but encountered a much different machine upon arrival in Germany:

Lily: I actually, I spent a month in Germany with another research team, and they had an instrument by a different company that's based in Germany, and everything was really big. I had to stand on things to be able to see and reach, and I physically couldn't do a lot of the transfers by myself because I just couldn't, I didn't have the arm span to reach.

$A G$ : Is it made for bigger people?

Lily: Well, this is my theory. It's made by a German company and a lot of German people, especially men, are like, large, and our instrument is made by a Japanese company, and Japanese people are quite small. I didn't clue in until I came back home and everything was easy, and in reach again and I was like "I wonder" but you know, it could very well be.

AG: Is there a reason why it would be made bigger? Or it just was.

Lily: No, I think it just was. There was no real necessity for it. It was essentially the same kind of instrument, but in a different country.

In this case, the design of the STM was accessible only to certain physicists, to whom it delegated gendered roles, actions, and responsibilities. As a smaller-framed woman, Lily was limited by her stature in her work with the STM, and was required to reposition herself as an expert in relation to the machine. Although she conducted the same experiments on this larger STM, rather than manipulating the sample herself, Lily required the help of larger men who could physically transfer the material to the microscope stage. This task required an arm-span much greater than her own, and a great deal of strength to maneuver the sample within the ultrahigh vacuum. While Lily never expresses a concern about this gendered division of labor explicitly, we refer back to Halberstam's [33] assertion that masculinity can be most powerful when its natural association with men is unchallenged. In light of this, we find that Lily's attribution of the difference in machine size to nationality rather than directly to men's bodies, compelling. It speaks to the often implicit ways that gender, in particular masculinity, is associated with the practice of experimental physics, and even the tools that are used in this practice. We will address this normalization of gender roles further in the discussion section.

\section{Physically skilled physicists}

The STM Lily used at Eastern University was also very large, and while she could manipulate it herself, it often required help from others to complete a task. However, while Lily was generally able to participate in all of the tasks on this machine, the instrument she used in Germany was an exception, and her ability to use it fully was constrained. Rather than perpetuate the gendered division of labor the machine demanded, Lily repositioned her expertise in the process of sample preparation for this instrument, and thus gained recognition as technically competent in new ways, and securing her inbound identity trajectory in this new lab environment. Lily explained that the delicate nature of sample preparation benefited from a handler with small hands and steady fingers. As such, Lily indicated that she developed a proficiency at tasks that were "finicky and small" and that dealt with "small things, small tools, and small fragile elements." In doing this, Lily gained recognition as an expert at manipulating the samples to be viewed in the STM, and refigured the kind of work that is generally inscribed with femininity. Lily stressed the importance of creativity and craftiness: "Often for us in the lab, a crafty side is quite helpful [...] shaping a piece of wire into a tool, using thin foils as parts or springs, etc."

Berg and Lie [50] have argued that machines are often built with gender in mind. When Lily was faced with a new machine that appeared not to be designed for a person of her stature, she set out to reposition herself as a physically skilled physicist in new ways that challenge the gendered assumptions implied in the construction of the STM. However, while she was able to gain recognition as a competent and physically skilled physicist in new ways, this new role demanded that she seek help from the men in her lab to conduct her experiments. This set up a practice where the division of labor was defined in ways that reinforced gendered power. The engineering of an instrument as the one in Germany that was too large for a woman, slight man, or person with a disability relegated the use of the instrument to only large, able-bodied men (or exceptionally tall women), and constrained the possibilities that others may perform recognizable physically skilled physicist identities through its use.

\section{Rejection of traditional femininity}

Ruby was a 3rd year doctoral student in astrophysics who struggled to achieve recognition by the accepted indices for competence in her field. Although Ruby's work is not considered experimental per se, it does involve extensive work in a lab setting-taking telescopic measurements, coding and troubleshooting, and repairing 
computers and servers responsible for running code. We thus regard this learning environment as similar to an experimental lab environment as it involves similar levels of interactions with colleagues and with machines, and while practical skills are not as emphasized in this environment, analytical skills certainly are, and are associated with masculinity in similar ways, as described by Wacjman [34] (see above).

Ruby's struggle to achieve academically was new and situational, and posed a crisis of identity for her as she had long identified with physics and physicists, and found that she associated strongly with the stereotypical masculinities in the field. Walker [46] has described stories that women engineers tell of their childhood aptitudes for science and early curiosity as ways of positioning themselves as natural insiders to the field. Ruby does this often, telling of stories from her adolescence and undergraduate years that brought her great success in physics, and positioned her at the top of her class. In our interviews, Ruby told me many times that she was a straight $\mathrm{A}$ student before her doctorate, and students would often come to her as the expert or source of information for all things physics. However, the analytical work that Ruby conducts with her research lab has presented a challenge to her. She began to realize that her expectations for graduate school were very different from the realities of research and that pulsar research "is one of the fields where astrophysics is the furthest from the romantic idealistic old fashion astronomy." The work she found herself doing was far away from the observational astrophysics she had become fascinated with.

Yeah, and then I was completely disillusioned when I started grad school 'cause nobody does the work; nobody like sits in front of a telescope...I basically just read numbers coming out of an X-ray detector. It is true the detector is pointing at the sky but it is not the same thing.

This disparity between the expectations for research and its realities are significant for Ruby, and she finds herself lagging behind the rest of her cohort, struggling to keep up with the challenges of coding and data analysis. Yet, Ruby still positions herself as an insider to the physics community; however, she does not rely on the usual forms of recognition (analytical or technical competence) to achieve this. Rather, Ruby positions herself as different or other to nonphysicist women and traditional femininity. She takes this position with Allison, as she describes herself in an interview:

In general, I don't care what I wear, and lots of physicists don't care what they wear-or some of them, anyway. Girly girls are something else, I can't stand girly girls, I don't think you are a girly girl, don't worry.

Walker [46] has described ways in which women engineers position themselves as different to stereotypical femininity as a way to assert an insider identity to the discipline. Ruby's story is an example of rejecting discourses of stereotypical femininity, as a way to position herself as an insider to physics. By positioning femininity outside of physics, Ruby simultaneously positioned herself as different from what Ong [51] called ordinary women (who perform traditional femininity). This has also been observed by Henwood [45] and Walker [46], who observed women engineers taking up identity positions as different from other women "who remain, by definition, weak and unable to cope in a man's world" [45] (p. 41). Later in one of our interviews, Ruby asserts "I just find that physics and the girly girl...there's a contradiction somewhere." Although Ruby struggles to be recognized as a physicist through the technical and analytical forms of confidence that are typical forms of currency in her department, she still asserts her identity as a physicist by positioning herself in opposition to traditional femininity. Ruby identifies herself as a physicist often in our interviews, suggesting that some of her performances fit that of an eccentric physicist:

I wear sandals, and I don't exactly mind that. I am wearing a slightly older $t$-shirt, so appearance eccentricity and sometimes behaviour eccentricities, I sometimes do horde them, so yeah, so I sort of am part of those people.

Others in the study have described stereotypical physicists in similar ways, almost all indicating that those performing these eccentricities were generally men. In this case, it seems that Ruby did not recognize herself by any of the indices of technical or analytical competence for physicists. However, Ruby did recognize herself as a physicist (and was recognizable to others) by her attire and behaviors. Thus, unlike Lily who finds a way to achieve recognition by redefining competence and challenging the identity position that is typically reserved for men, Ruby carves out her identity trajectory to membership in the physics community by performing an identity that is in line with the stereotypical physicist often associated with masculinity.

\section{Case study 3: United States}

The third case study is a two-year ethnographic study among experimental plasma physicists in a laboratory in the United States. The field work was situated in a large university laboratory in plasma physics at a large university campus in the western part of United States with laboratories smaller compared to Big Science labs. Still, the campus maintains experimental facilities like tokamaks and accelerators. Based on Pettersson's observations of the physicists' work, the machines, and the low amount of women in the lab, Pettersson's curiosity of gender relations and plasma physics was triggered. Through daily practices 
and hands-on situations, the physicists defined their experimental work as strongly associated with masculinity. Through observations and in-depth interviews, the practices and discourses in physics were analyzed as marks of identity for the laboratory and for the group of physicists within. The physicists' work with the experiments were marked with connotations of a craft, of strength, and physical efforts, and thereby defining knowledge making in experimental physics as knowledge embodied. Here, we operationalize Halberstam's argument that the discourse of masculinity as "nonperformative" normalizes the naturalness of masculinity to deconstruct how masculinity in the lab environment is constructed via the male body. This idea is constructed in parallel with Wacjman's technical masculinity through a "boys and their toys" discourse, associated with physical and technical skills. Later, it is discussed how physics as an activity was defined among the informants. We shall see which activities were in the core of the lab and central in the physicists' definition of basic and necessary knowledge for doing good physics and in what respect this is related to masculinity. We will explore how we can understand this in terms of identity work. ${ }^{1}$

\section{Making gender preexperimental work}

The making of gender in the experimental physics lab is not a process that starts in the lab. As the gendered aspects of physics are discussed in the two previous cases in this article vis-à-vis educational context, here the making of gender is discussed with respect to the practices of experimental plasma physicists. In the data presented here, the informants in this study reflect on both the gendered context during elementary and high school as well as at the university level.

In response to a prompt about educational history, one of the informants in the study pointed at the preuniversity educational context as a pipeline in to or from science and physics. In a response that illustrates Halberstam's concept discussed previously, he highlighted what he called an assumed relationship between boy's natural talents for the sciences and its consequences when it comes to specialty in school and later at university. By the time the boys and the girls are in high school, he said, a selection process has already started:

\footnotetext{
${ }^{1}$ Women in physics inhabit a position that Haraway calls the "inappropriate/d other", a metaphor borrowed from Trin Minhha. To be an inappropriate/d other does not necessarily aim at someone who is outside. Haraway defines the position of an inappropriate/d other as someone who is critical, and who diffracts. To be an inappropriate/d other is to not entirely fit in to the taxonomy of the given cultural space. Also, as such, you become dislocated from the available schemas that specify actors and narratives; in this case the culture of plasma physics and its environment [52] (see also Ref. [53]). Also compare with Valian's discussion on gender schemas and expectations among female academics in Ref. [54].
}

The boys are good at it and already know that they are good at it! Like... It has nothing to do with who they are! [Laugh] Necessarily! It's just that assumptions get made and that's what they get taught! So, by the time you're taking Calculus, you know, higher level science, math, physics, calculus as a high school oral, as you should be if you're gonna become a physicist... you have already weeded out half the girls who had the skills! Because even though they had the skills, they got told that they didn't or that they weren't as good as the guys.

Similarly, one of the postgraduate students within the lab made critical reflections on the relationship between gender, expectations, and physics in general. According to him, an assumption about boys' and girls' "natural relationship [to the sciences] is made first, then the feedback is given, and the children learn this [in schools]." These understandings have consequences for young people's trajectories into physics practices. According to Pajares [55], gender differences related to self-confidence in science begin as early as in middle school or junior high school. This is amplified through senior high school and college. Girls are reported to have less confidence; boys develop greater confidence through "experience developing relevant skills" [56] (p. 22). As Hill, Corbett, and St. Rose point out, students who lack confidence in science and math, are less likely to feel attracted to tasks that require such skills (see also Ref. [5]).

One junior physicist reflected on the possibility of changing teaching methods, thus competing with prejudices and assumptions in the classroom:

You know, I don't know if there's really about the curricula, or if it's just about, you know, teaching something that's new and having different assumptions, but like... In my mind, I see it as assumptions getting made, that women aren't gonna do this, aren't gonna be good at it.

One explanation for the gender divide in physics that emerged from informants was that of biological differences. In an interview, one informant stated that women simply are not fitted for science. During the field work, only a few persons talked about the possible relationship between biological causes between science, gender, and biology openly. One of the female physicists was anxious about not being victimized when talking about gender, but lowered her voice when referring to her colleagues and their opinions about women in physics:

You know, I am so happy that you are asking about men and physics. Otherwise, it is always about women [sigh]. I mean, there are people HERE saying that there shouldn't be women in physics! Here, in this lab.

However, the relationship between gender and talent in science and physics was sometimes uttered in daily 
conversations, thus putting gender in the physics lab at an everyday level. Physical strength and practical work, as discussed further in this article, was defined as part of real physics. To not be able to perform with strength was to disqualify a person for being a good experimentalist.

An invective used to comment on someone's work or their mood was the use of the word "chick." "Don't whine like a chick" or "Don't act like a chick," was a perfunctory comment used between male Ph.D. students when someone complained about a practical working task or a writing session. These comments referred to women as being incapable of conducting a good job in physics, conversations that I as an ethnographer overheard during lunch or coffee breaks, but also when practical work was conducted in the lab. These types of comments created uneasiness among the few female physicists in the lab. Not only did the comments disqualify their abilities to conduct physics; they also suggest that no one openly would argue that women are incapable of science face to face, even though their gender was used as an insult. In addition, for a couple of days every year, there was a cleaning session in the large device hall. The entire hall was to be tidied up and the large devices deconstructed and thoroughly cleaned. Since I myself was unskilled dealing with the physicists work, I decided to sort nuts and screws, blotting paper, grease cans, and clean the tables with a cloth. The senior physicists led the job and told the junior ones what to do. To my surprise, the female Ph.D. students joined me, and said they were to sort the tools (hammers, scissors, nut- and screwdrivers, and similar) with me and then clean the floor and dust. The male Ph.D. students were found organizing and cleaning measuring tools, taking the devices apart, cleaning the cathode, and thus learning how the device was constructed, while the female physicists brushed the floor and whisked the dust away. This gendered division of labor reflected the derogatory language used to describe work in the physics labs. Doing work like a chick or like a woman, often referred to the kind of menial tasks implicitly assigned to women, which clearly carried less importance in the hierarchy of labor in the lab environment.

When analyzing an arena such as the plasma physics laboratory, the relationship between homosociality (a nonsexual relationship of solidarity among men) and machines becomes crucial for understanding the gender dynamics and the ways in which practices in experimental plasma physics are gendered. As mentioned, ideas about men's brains and natural ability to conduct physics were clearly articulated, and support Halberstam's [33] argument that the nonperformative conception of masculinity can normalize masculinity and give power to those naturally associated with it. But the existence of a symbolic relationship between the practice involving machines, experimental plasma physics, and gender was also articulated by junior and senior physicists. Social and cultural bonds between skills in science, machines, and men were made at an everyday level, as well as at a symbolic level [57]. As Mellström highlights, there are taken for granted "masculine homosocial bonds," mediated through the interaction with men and machines [58] (p. 17). We see these reinforced through the implicit gendered division of labor in the laboratory. The relationship between homosociality and machines is central to studies of experimental science, where machines and large technical devices are central parts of the scientific practice.

\section{Making physics through machine building}

As pointed out by Wajcman and Cockburn, domestic technology mirrors constructions of gender and technology. The relationship between women and domestic technology and men and workplace technology emerged with the development of the engineering profession $[59,60]$; see also Ref. [61]. As a result, Wajcman writes, "muscles, skill, strength, dexterity, rationality and labour time became the preserve of men and important power resources" [62] (p. 780).

One informant used a well-known notion of men, machines, technology, and tools; the notion of boys and their toys. This informant even pointed explicitly to a "sort of this culture of boys and their toys in plasma physics." Plasma physics as an experimental science was also talked of as a scientific field with exclusive high power equipment and powerful machines:

Boys are brought up in big trucks! And tractors! Once you drive a car, you want a big fast thing! You know. If that's your kind of THING, well, then you're actually going to be pulled in to plasma physics! 'Cause there's some REALLY HIGH POWER, SEXY, EXOTIC EQUIPMENT IN THERE!

Relationships between men and machines were talked about with references to everyday life as the work in the lab, as a connection interlinked with each other. "Physicsplasma physics - is about big high power toys. Which is sort of a classical male thing in this country" said a junior physicist (see Refs. $[63,64])^{2}$ "Physics is not only about theoretical knowledge and formulas. Physics is about skills, building and constructing," said one of the senior physicists in the lab. According to the informants, experimental physics is not about theory and math. "It is foolish" to take that standpoint, said a senior member in the lab. "Sure, you need to do your math, but you cannot conduct experiments if you cannot build your machines and devices." Actively contributing to an environment with tools and machines is contrasted with physicists' working

\footnotetext{
${ }^{2}$ The relationship between "boys and their toys" has also been highlighted in the management literature, for example [63], where men and "toys" a.k.a. "gadgets" are interlinked. Also see Ref. [64] for discussion on the relationship between toys, masculinity, and the automobile shop floor.
} 
with theory. The latter was described as work distanced from reality, missing knowledge how an experiment is set up, how the equipment is built, and how an experiment is run for collecting real data and being able to control one's experimental setting.

A person with experience of building experimental devices and machines was defined as a highly valuable co-worker in the lab. For certain, academic rank and title was considered to be important; rank dectermines the possibility to supervise postgraduate students. Daily conversational markers like "I love to get my hands dirty!" was a repeated sentence by the grad students as well as the senior lab members. The hands-on knowledge and skills to build is what really makes a fellow physicist specifically precious. Here in the lab, you do labor, said the head of the lab. That means to get greasy and dirty, to lie under machines and to lift heavy things. With labor, he refers to bodily work, and not necessarily activities related to intellectual work. Moreover, it relates to working at a shop floor, and as such several physicists talk about it as manual work [65].

Given the demands of being an experimental plasma physicist with practical skills, the practical work included handling tools from stationary saw blades and drilling machines, and cutting tools, to soldering irons, screw- and nut drivers, and wrenches. The emphasis on the practical work can be interpreted as constructing a boundary against other fields of physics, claiming the uniqueness of being both a plasma physicist and an experimentalist. To conduct labor was highly romanticized. When the lab's largest plasma device was built, several senior members of the current lab were the ones who did the actual building. At that time, said one of the senior physicists, they did not have the luxury of having technical staff employed to help them with parts of the construction process. That also assumed that those people who were a part of the building process of the device also were the people who possessed the most knowledge about the entire machine.

However, when one of the few women in the lab received attention for experiments conducted and papers published in high prestigious journals, she was not recognized for her experimental skills. During interviews she and her colleagues were asked why she was so successful. Both she and her colleagues said that her success was due to her communication skills, not her experimental skills; she was able to tell other people what to do and to design experiments, thus, not a real physicist according to the norm in the laboratory. Thus, the indices by which a female physicist in this context was recognized were not the same as those physical skills that helped male physicists gain recognition for similar work. A real physicist in this context is one who performs the technical masculinity [34] in recognizable ways. It is narrated again and again, and a part of the narrative is who is becoming a physicist and on what grounds. Such narrations are the spoken (and unspoken) values regarding gendered abilities related to science and technology. One of the junior physicists reflected on the environment in the lab, and if the lack of women was related to a certain male culture or structures.

And I think that is that... that the atmosphere is gendered and there are assumptions that are made about [...]. I don't know exactly how to analyze why that environment is so unfriendly to women. Or is unfriendly to women, why women might be put off by it or whatever, but... whether it's just machismo or if it's something more settled.

When analyzing men as a political category, we can explore how gender is constructed through identity forming practices and interactions in science [66-68]. Through defining real physics in experimental physics as labor, gender is also included in the process of creating boundaries towards other fields of physics. Embodied abilities and the desired hands-on skills of an experimental physicist in the lab are everyday expressions of masculinity. This does not imply that developing a masculine identity is an active strategy among the lab members. However, the ideals in relation to the hands-on situation are noteworthy masculine ideals of gender that even the lab members highlight. The environment for the plasma physicists can be described as an environment that still contains aspects of stereotypical masculinity. It therefore becomes crucial to analyze the meaning of physics and real work among the plasma physicists. Gendered values embedded into machines are one aspect, and this is highlighted by the informants.

\section{DISCUSSION}

Taken together, these three case studies provide a novel perspective on identity constitutions within physics communities and demonstrate how the heterogeneity of practices in physics, although strongly associated with masculinity, is embodied by students and researchers in complicated ways. By utilizing a theoretical framing that considers the performativity of masculinity across both men and women, albeit taking into consideration that certain masculinities as more easily performed by certain bodies than others (as demonstrated by the case of Lily), we are able to consider how masculine ideals are negotiated by and taken up also by female physicists. For instance, as part of their identification with physics culture, women in both the Swedish (Anne and Cecilia) and Canadian (Ruby) case studies reject traditional femininity, and may be seen as performing a type of female masculinity instead [33]. Further, the commonalities between the cases tell us much about the kind of identity work required to become a female physics student, and the gendered expectations that female students encounter. The case of Lily similarly demonstrates a negotiation of gendered expectations in a discipline where the technical masculine identity is assumed to be the norm, and thus requires females to find new ways to position 
themselves as competent. This demonstrates that female students must not only navigate the masculine norms of a discipline, but also negotiate the limited possible identities for female students in physics. We see this clearly in case study 3 where recognition is afforded differentially to men and women, and success in the field for a woman is not attributed to her performance of physical skill or the technical competence associated with masculinity, but rather to her abilities in communication-a characteristic often associated with femininity. Interestingly, it emerged that often female students don't explicitly regard gender as an important issue in their practice. This has been address previously in research on engineering education $[45,46]$. In particular, Walker's work is helpful to explain how often practitioners themselves don't see gender as a problem. She suggests, "the women's ambivalence or even rejection of a gendered explanation suggests processes of normalization rather than gender equity at work" [46] (p. 82). Thus, we feel these instances where gender is not explicitly acknowledged are important to highlight as a way of understanding the processes at work that position masculinity as the default ideology of the discipline.

An important finding emerging across all three case studies is a strong emphasis on physical skill, the ability to use machines, and an emphasis on creativity or tinkering in relation to the use of machines. In the first case study we see the importance that students place on tinkering as a way to simultaneously identify with the skilled physicist position and to resist the rule following that students learn to associate with femininity (and by extension disassociate with physics). In the second case study we learn that the position for physically skilled physicist is designed into the machinery constructed to study nanoparticles in solid state physics. We see that for female physics students to perform a recognizable competent physicist identity requires a reworking of physically skilled physicist identity in ways that challenge the gendered assumptions implied in the construction of machinery. Similarly, in the third case study we see the use of a boys and their toys discourse where playing with large complex machinery is regarded as a male thing, thus confirming the findings from the other case studies that performances of masculinity in physics are constructed through tinkering with instruments designed for larger (male) bodies. This finding is an important consideration for physics education research, as it brings into relief the ways that masculinity is associated with various forms of laboratory work, and, subsequently, the kinds of performances that are recognized through physics practices.

While we noticed many commonalities across the cases, each case raises different concerns. Danielsson's analysis challenges the taken-for-granted notion that male physics students have an unproblematic relation to their chosen discipline. In a different vein, we see the case of Lily as presented in Gonsalves' case study as an example of a student challenging the gender norms for machine work by gaining recognition for her competence with fragile and finicky work. This flip of the gender script permitted Lily to refigure the kind of work that is generally associated with feminized labor practices [69] in order to gain recognition for an otherwise typically masculinized practice. Finally, we can see that in Pettersson's study the technical skill of the shop floor worker [34] can be highly masculinized and valued among plasma and experimental physicists in ways that position these practices in opposition to the calculating analytical physicist described by Wacjman. The rejection of theory in favor of experimental data is again another example of how the practices valued in various research contexts are hetereogeneous, while at the same time embedded in masculinity.

Emerging from these case studies is thus a more nuanced portrait of disciplinary and culturally specific constructions of masculinity and identity in relation to physics education and practice. Importantly, we see that while gender is not an explicit part of the narrative of all of the participants in these studies, we are able to identify various constructions of masculinities associated with the technical and analytical skills required to perform and be recognized as a competent physicist. The studies presented here and others before them (see Refs. [70,71]) demonstrate that many students and practitioners in physics operate largely within individualistic discourses that attribute success and academic achievement with individual skills and motivation. This is important for physics education researchers who wish to equip students with skills for making sense of their participation in physics in ways that position the practice of physics within a structure of larger, intersectional social forces that shape our understanding of these practices, and who we recognize as successful in them. Physics as a discipline may often be constructed as independent of societal factors, but Harding claims that the abstractness and the formality of physics need to be understood as "distinctive cultural features, not the absence of all culture" [72] (p. 61). In a similar vein, Traweek [1] characterized physics as "a culture of no culture." Getting sight of the cultural production of physics and the related identity negotiations may therefore be difficult, in particular, given how the practice is so strongly interlinked with masculinity. However, the laboratory as an arena for masculine performances is not a static environment-it is open to change. If, in physics education research, we choose to open up laboratory practices for an analysis through the lens of masculinity studies, it may also be possible to better understand the under-representation of women in physics. We note, however, that studies of masculinity and physics should not address either as isolated phenomena or as phenomena that are only relevant to men. They should be understood in relation to women's experiences in physics, and within the academy, the focus may then shift to an examination of why certain forms of knowledge are gendered and why these gender boundaries still prevail. 
[1] S. Traweek, Beamtimes and Lifetimes. The World of High Energy Physicists (Harvard University Press, Cambridge, MA, 1988).

[2] J. Hermanowicz, Lives in Science: How Institutions Affect Academic Careers (University of Chicago Press, Chicago, IL, 2009).

[3] C. Hasse, Gender diversity in play with physics: The problem of premises for participation in activities, Mind Cult. Activ. 9, 250 (2002).

[4] H. Pettersson, Making masculinity in plasma physics: Machines, labour, and experiments, Sci. Stud. 24, 47 (2011).

[5] E. F. Keller, Reflections on Gender and Science (Yale University Press, New Haven, London, 1985).

[6] S. Harding, The Science Question in Feminism (Open University Press, London 1986).

[7] K. Barad, A Feminist approach to teaching quantum physics, in Teaching the Majority: Breaking the Gender Barrier in Science, Mathematics, and Engineering, edited by S. V. Rosser (Teachers College Press, New York, 1995), pp. 43-75.

[8] K. Due, Who is the competent physics student? A study of students' positions and social interaction in small-group discussions, Cult. Stud. Sci. Educ. 9, 441 (2014).

[9] L. Schiebinger, Has Feminism Changed Science? (Harvard University Press, Cambridge, MA, 1999).

[10] K. Rolin, Gender and physics: A theoretical analysis, J. Women Minorities Sci. Eng. 7, 1 (1999).

[11] A. T. Danielsson, Exploring woman university physics students 'doing gender' and 'doing physics', Gender Educ. 24, 25 (2012).

[12] A. T. Danielsson, Gender in physics education research: A review and a look forward, in Never Mind the Gap! Gendering Science in Transgressive Encounters, edited by M. Blomqvist and E. Lindsmyr (Centre for Gender Research, Uppsala, Sweden, 2010).

[13] Re/structuring Science Education: Reuniting Sociological and Psychological Perspectives, edited by W. M. Roth (Springer, New York, 2010).

[14] I. Rodriguez, R. M. Goertzen, E. Brewe, and L. H. Kramer, Developing a physics expert identity in a biophysics research group, Phys. Rev. ST Phys. Educ. Res. 11, 010116 (2015).

[15] J. P. Gee, Identity as an analytic lens for research in education, Rev. Res. Educ. 25, 99 (2000).

[16] H. Carlone and A. Johnson, Understanding the science experiences of successful women of color: Science identity as an analytic lens, J. Res. Sci. Teach. 44, 1187 (2007).

[17] Z. Hazari, G. Potvin, R. H. Tai, and J. Almarode, For the love of learning science: Connecting learning orientation and career productivity in physics and chemistry, Phys. Rev. ST Phys. Educ. Res. 6, 010107 (2010).

[18] T. Scott, Z. Hazari, and G. Potvin, Interdisciplinary Thinking and Physics Identity, 2013 PERC Proceedings (Portland, OR, July 17-18, 2013), edited by P. V. Engelhardt, A. D. Churukian, and D. L. Jones (American Association of Physics Teachers, College Park, 2013), pp. 329-332.
[19] J. Cresswell, Qualitative Methods and Research Design: Choosing among Five Approaches (Sage Publications, Thousand Oaks, CA, 2012).

[20] M.-G. Sere, Towards renewed research questions from the outcomes of the European project labwork in science education, Sci. Educ. 86, 624 (2002).

[21] Y. Engeström, Learning by Expanding: An ActivityTheoretical Approach to Developmental Research (Orienta-Konsultit, Helsinki, 1987).

[22] J. Lave and E. Wenger, Situated Learning: Legitimate Peripheral Participation (Cambridge University Press, New York, 1991).

[23] J. P. Gee, An Introduction to Discourse Analysis: Theory and Method, 2nd ed. (Routledge, New York, NY, 2005).

[24] C. Paechter, Masculinities and femininities as communities of practice, Women's studies international forum 26, 69 (2003).

[25] E. Wenger, Communities of Practice. Learning, Meaning and Identity (Cambridge University Press, Cambridge, England, 1998).

[26] C. West and D. H. Zimmerman, Doing gender, Gender and Society 1, 125 (1987).

[27] J. Butler, Gender Trouble: Feminism and the Subversion of Identity (Routledge, New York, NY, 1990).

[28] C. F. Paechter, Being Boys, Being Girls: Learning Masculinities and Femininities (Open University Press, Berkshire, England 2007).

[29] W. Faulkner, 'Nuts and bolts and people': Gender-troubled engineering identities, Social Studies Sci. 37, 331 (2007).

[30] R. Connell and J. Messerschmidt, Hegemonic masculinity: Rethinking the concept, Gender and Society 19, 829 (2005).

[31] M. Kimmel, Manhood in America: A Cultural History (Free Press, New York, 1996).

[32] R. Howson, Challenging Hegemonic Masculinity (Routledge, London, 2006).

[33] J. Halberstam, Female Masculinity (Duke University Press, Durham, NC, 1998).

[34] J. Wajcman, Feminism Confronts Technology (The Pennsylvania State University Press, University Park, PA, 1991).

[35] J. Wajcman, The masculine mystique. A feminist analysis of science and technology, in Pink Collar Blue: Work, Gender and Technology, edited by B. Probert and B. W. Wilson (Melbourne University Press, Melbourne 1993).

[36] S. Kvale, InterViews: An Introduction to Qualitative Research Interviewing (Sage Publications, Thousand Oaks, CA, 1996).

[37] A. T. Danielsson, Uppsala dissertations from the faculty of science and technology, 2009.

[38] A. Gonsalves, Empirical dissertation, McGill University, Faculty of Education, 2010 (unpublished).

[39] H. Pettersson, Boundaries of masculinity and plasma physics: Toward an understanding of the making of masculinities in experimental physics, in Transforming Substance: Gender in Material Science (Crossroads of Knowledge/Center for Gender Studies, Uppsala, Sweden, 2013). 
[40] A. Hofstein and V. N. Lunetta, The laboratory in science education: Foundations for the twenty-first century, Sci. Educ. 88, 28 (2004).

[41] S. L. Star and J. R. Gricsemer, Institutional ecology, 'Translations' and boundary objects: Amateurs and professionals in Berkeley Museum of Vertebrate Zoology, 1907-1939, Soc. Stud. Sci. 19, 387 (1989).

[42] K. Thomas, Gender and Subject in Higher Education (Open University Press, Buckingham, UK, 1990).

[43] U. Mellström, Engineering Lives: Technology, Time and Space in a Male-Centred World (Linköping Studies in Art and Science, Linköping, 1995).

[44] X. Y. Du, Gendered practices of constructing an engineering identity in a problem-based learning environment, Eur. J. Eng. Educ. 31, 35 (2006).

[45] F. Henwood, Engineering difference: discourses on gender, sexuality and work in a college of technology, Gender Educ. 10, 35 (1998).

[46] M. Walker, Engineering identities, Br. J. Sociol. Educ. 22, 75 (2001).

[47] E. Kvande, 'In the belly of the beast' constructing femininities in engineering organizations, Eur. J. Women's Studies 6, 305 (1999).

[48] E. Seymour and N. M. Hewitt, Talking about Leaving. Why Undergraduates Leave the Sciences (Westview Press, Boulder, CO, 1997).

[49] H. Mendick, A beautiful myth? The gendering of being/ doing 'good at math', Gender Educ. 17, 203 (2005).

[50] A.-J. Berg and M. Lie, Feminism and constructivism: Do artifacts have gender?, Sci. Tech. Hum. Val. 20, 332 (1995).

[51] M. Ong, Body projects of young women of color in physics: Intersections of gender, race, and science, Social problems 52, 593 (2005).

[52] D. Haraway, Simians, Cyborgs and Women: The Reinvention of Nature (Routledge, New York, 1991).

[53] H. Pettersson, dissertation Umeå: Umeå University, 2007 (unpublished).

[54] V. Valian, Why So Slow? The Advancement of Women (MIT Press, Cambridge, MA, 1999).

[55] F. Pajares, Gender differences in mathematics self-efficacy beliefs, in Gender Differences in Mathematics: An Integrative Psychological Approach edited by A. M. Gallagher and J.C. Kaufman (Cambridge University Press, New York, 2005), pp. 294-315.

[56] C. Hill, C. Corbett, and A. St. Rose, Why So Few? Women in Science, Technology, Engineering, and Mathematics (AAUW, Washington, DC, 2010).
[57] W. Faulkner, The technology question in feminism: A view from feminist technology studies, Wom. Stud. Int. Forum. 24, 79 (2001).

[58] U. Mellström, Masculinity, Power and Technology. A Malaysian Ethnography (Aldershot, Ashgate, 2003).

[59] J. Wajcman, TechnoFeminism (Polity Press, Cambridge, MA, 2004).

[60] C. Cockburn, Brothers: Male Dominance and Technological Change (Pluto Press, London, 1983).

[61] R. Oldenziel, Making technology masculine: men, women and modern machines in America, 1870-1945 (Amsterdam University Press, Amsterdam, 1999).

[62] J. Wajcman, New connections: social studies of science and technology and studies of work, Work Employ. Soc. 20, 773 (2006).

[63] Boys and their Toys. Masculinity, Class, and Technology in America, edited by R. Horowitz (Routledge, London, 2001).

[64] B. Adler, Jr., Boys and their Toys. Understanding Men and their Relationship with Gadgets (AMACOM, New York, 2007).

[65] S. Meyer, Work, play and power. masculine culture on the automotive shop floor, 1930-1960, in Boys and their Toys. Masculinity, Class, and Technology in America, edited by R. Horowitz (Routledge, London, 2001).

[66] F. Ashe, The New Politics of Masculinity: Men, Power and Resistance (Routledge, London, 2007).

[67] R. W. Connell, Masculinities (University of California Press, Berkeley, CA, 2005).

[68] J. Hearn, Theorizing men and men's theorizing. Varieties of discursive practices in men's theorizing of men, Theor. Soc. 27, 781 (1998).

[69] A. Pepper, Sexual divisions of labour in exportoriented manufacturing sectors: The reconstruction of gender and the urbanization of production in the Global South, Consilience: J. Sustainable Develop. 8, 142 (2012).

[70] L. Erwin and P. Maurutto, Beyond access: considering gender deficits in science education, Gender Educ. 10, 51 (1998).

[71] A. Lundborg and K. Schönning, Maskrosfysikergenusperspektiv på rekrytering, handledning och arbetsmiljö bland Uppsalas fysikdoktorander. [Dandelion physicists-gender perspectives on recruitment, supervision and working environment among the $\mathrm{PhD}$ students in physics in Uppsala] Uppsala: Universitetstryckeriet, (2007).

[72] S. Harding, Is Science Multicultural? Postcolonialisms, Feminisms, and Epistemologies (Indiana University Press, Bloomington, IN, 1998). 